\title{
Sanitary wares (Wash-basin) product industry situation and quality analysis
}

\author{
Wen Yin ${ }^{1}$, Kaifang Wang* \\ ${ }^{1}$ Lianyungang Comprehensive Inspection and Testing Center for Quality and Technology ,Lianyungang,Jiangsu,China,222000 \\ ${ }^{*}$ China Building Material Test \& Certification Group(Shaanxi) Co. Ltd, Xi'an, Shaanxi, China, 710049
}

\begin{abstract}
Sanitary ceramic products refer to glazed ceramic products used for sanitary installations.Sanitary wares products are divided into ceramic Sanitary wares and ceramic Sanitary wares according to different materials.According to use divide for implement kind, basin kind.The urinal type includes sit urinal, squat urinal, urinal;The basin category includes the Wash-basiner, washing tank, mop pool and so on.Among them, the Wash-basiner refers to the glazed ceramic products used for washing face and hands. It is a necessary sanitary equipment in family or public places and has become an essential sanitary appliance in people's life.
\end{abstract}

\section{Introduction}

In the past 20 years, China's building Sanitary wares industry has been developing rapidly. With large-scale industrial production, China's building ceramics industry has emerged several major ceramic production areas such as Guangdong, Fujian, Sichuan, Jiangxi, etc. There are about 1000 Sanitary wares production enterprises, with a total output of about 200 million pieces.China's Sanitary wares output has accounted for about $55 \%$ of the global total, China's Sanitary wares export share accounted for more than half of the international Sanitary wares trade, has become the world's largest producer, consumer and exporter.

With the continuous development of social economy, people's pursuit of quality of life is getting higher and higher.Now wash basin is no longer just the toilet a simple single face equipment, various types and various functions of high quality wash basin gradually become mainstream, wash a face is not only a product, the market demand for the entire sanitary ceramic products are gradually increasing, the next five years, Sanitary wares market will keep the momentum.

At present, the Sanitary wares products in China are mostly concentrated in the middle and low grade. According to statistics, $60 \%$ to $70 \%$ of the Sanitary wares in China are middle and low grade products, while the middle and low grade products in Japan only account for $20 \%$, and the rate of the middle and low grade products in Italy is even lower, only $2 \%-4 \%$.Many of the bosses of ceramic enterprises in Chaozhou are skilled workers from state-owned ceramics factories in the 1980s. They have not received systematic training in management knowledge, but mostly rely on experience to manage.With the intensification of competition, the domestic market low - price wholesale and other traditional sales model is difficult to continue.

\section{Analysis of product quality spot check}

The State Administration for Market Regulation (including the former General Administration of Quality Supervision, Inspection and Quarantine of the People's Republic of China) has organized four national quarterly supervision and spot checks on Sanitary wares (Washbasiners) products from 2016 to 2020.Sampling inspection involved 521 batches of products from 249 enterprises in 10 provinces and municipalities including Tianjin, Hebei, Shanghai, Jiangsu, Zhejiang, Fujian, Henan, Hubei, Guangdong, and Chongqing (excluding export products). The details of sampling inspection are shown in Table 1 and Figure 1.

Sanitary wares (Wash-basin) production enterprises are mainly concentrated in Henan, Guangdong and Fujian.Through summarizing the results of national supervision on product quality in the concentrated production areas of Sanitary wares (Wash-basiners) in four years, the quality distribution of Sanitary wares (Wash-basiners) products is analyzed, and the status of domestic Sanitary wares (Wash-basiners) industry is understood.See Table 2 and Figure 2 for details. 
Table 1 Statistical table of sampling inspection of Sanitary wares (Wash-basiners) products over the years

\begin{tabular}{|c|c|c|c|c|}
\hline NO. & Year & $\begin{array}{c}\text { Check the number } \\
\text { of samples }\end{array}$ & $\begin{array}{c}\text { Inspection number } \\
\text { of nonconformities }\end{array}$ & $\begin{array}{c}\text { Found rate of } \\
\text { nonconformity (\%) }\end{array}$ \\
\hline 1 & 2016 & 86 & 6 & 6.98 \\
\hline 2 & 2018 & 87 & 9 & 10.34 \\
\hline 3 & 2019 & 120 & 13 & 10.83 \\
\hline 4 & 2020 & 249 & 27 & 10.84 \\
\hline
\end{tabular}

\section{Random check statistics}

300

250

200

150

100

50

0

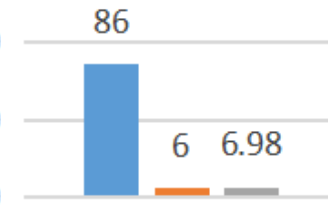

2016
87

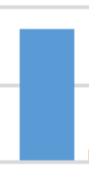

2018
120

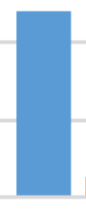

2019
249

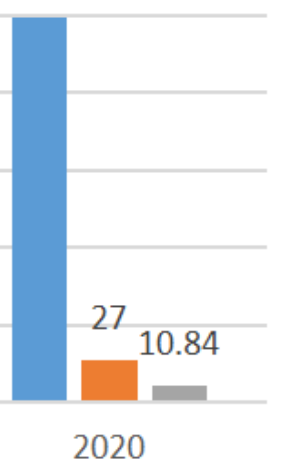

Inspection number of nonconformities

Check the number of samples

Found rate of nonconformity (\%)

Figure 1 Statistical figure of sampling inspection of Sanitary wares (Wash-basiners) products over the years

Table 2 Statistics the non-conforming detection rate of enterprises and products by different provinces and cities

\begin{tabular}{|c|c|c|c|c|c|}
\hline Year & Region & $\begin{array}{l}\text { Total number of } \\
\text { selected products } \\
\text { (pieces) }\end{array}$ & $\begin{array}{c}\text { Found rate of } \\
\text { nonconformity (\%) }\end{array}$ & $\begin{array}{l}\text { Spot check the } \\
\text { number of } \\
\text { enterprises }\end{array}$ & $\begin{array}{l}\text { Found rate of product } \\
\text { nonconformity (\%) }\end{array}$ \\
\hline \multirow{3}{*}{2016} & Guangdong & \multirow{3}{*}{86} & \multirow{3}{*}{7} & 40 & 12.5 \\
\hline & Henan & & & 22 & 4.5 \\
\hline & Fujian & & & 8 & 0 \\
\hline \multirow{3}{*}{2018} & Guangdong & \multirow{3}{*}{87} & \multirow{3}{*}{10.3} & 44 & 13.6 \\
\hline & Henan & & & 25 & 12 \\
\hline & Fujian & & & 7 & 0 \\
\hline \multirow{3}{*}{2019} & Guangdong & \multirow{3}{*}{120} & \multirow{3}{*}{10.83} & 89 & 12.36 \\
\hline & Henan & & & 12 & 8.33 \\
\hline & Fujian & & & 15 & 6.67 \\
\hline \multirow{3}{*}{2020} & Guangdong & \multirow{3}{*}{228} & \multirow{3}{*}{10.52} & 224 & 10.27 \\
\hline & Henan & & & 1 & 100 \\
\hline & Fujian & & & 3 & 0 \\
\hline
\end{tabular}




\section{Random check statistics}

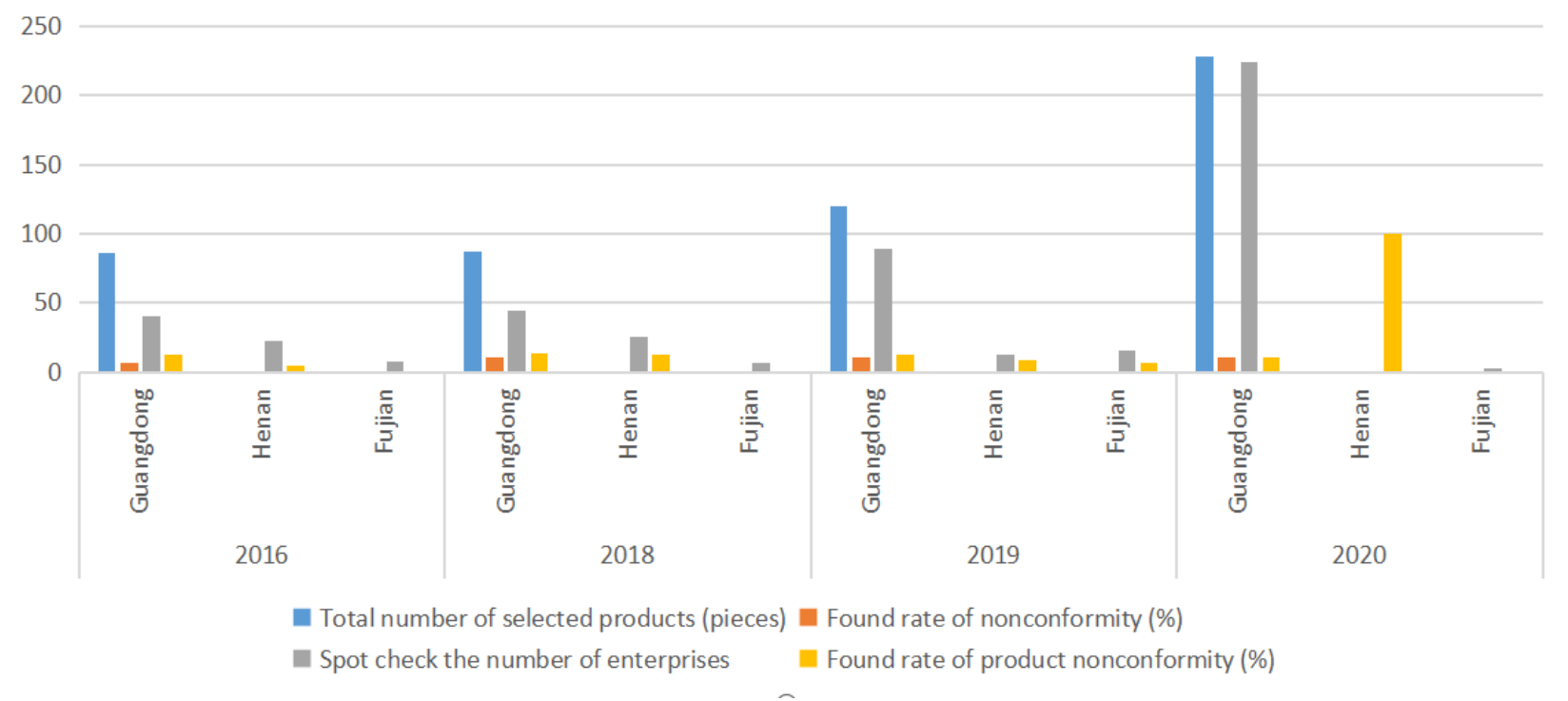

Figure 2 Statistics of unqualified rate of products in each province and city

\section{Cause analysis of quality problems}

Make a general survey of the results of nearly four times of national supervision sampling, especially the recent three years of continuous sampling results, national Sanitary wares (Wash-basin) product overall quality level maintains a long-term slightly higher than the level of $10 \%$.Unqualified production enterprises to small and medium-sized micro-enterprises, mainly concentrated in Guangdong, Henan, Fujian region.With the improvement of the number of sampling batches and sampling coverage, more and more non-conforming items were found.This shows that the quality level of sanitary ware furniture products in China still needs to be improved, and the product quality in each producing area may fluctuate, and it needs to be further consolidated and improved.It is necessary to further strengthen the publicity and implementation of standards, improve the quality awareness of production enterprises, consciously strengthen the internal quality management of enterprises, insist on not using the raw and auxiliary materials that do not meet the requirements of national standards, strengthen the incoming inspection of raw and auxiliary materials and the delivery inspection of products, and strengthen the management of all aspects of production.

In recent years, the random inspection results basically reflect the actual situation of the face cleaner product industry, the quality of large enterprises is stable, the quality of small and micro enterprises is unstable, and the rate of unqualified discovery is higher.Guangdong province and henan province is a large production of Wash-basin products, the scale of production enterprises and product quality is uneven, there are TOTO, Dongpeng, Annwa, Shanggao, Kohler and other large enterprises, there are also a large number of small enterprises.Large enterprises have independent research and development, mold production, parts production, product quality inspection in and out of the factory ability, product quality is guaranteed;And the small and medium-sized micro enterprise mold is not standard enough, can not make the product performance to achieve the optimal;And blindly rely on the pursuit of profits at low cost, ignoring the impact of the quality of raw materials on product performance;Most of the product quality inspection ability of small and mediumsized enterprises is poor, can not accurately determine the overflow function of the product, water absorption rate and other properties, the technical parameters of the product are not accurate.

Make a general survey of the results of nearly four times of national supervision sampling, especially the recent three years of continuous sampling results, national Sanitary wares (wash a face) product overall quality level maintains a long-term slightly higher than the level of $10 \%$.Unqualified production enterprises to small and medium-sized micro-enterprises, mainly concentrated in Guangdong, Henan, Fujian region.With the improvement of the number of sampling batches and sampling coverage, more and more non-conforming items were found.This shows that the quality level of China's Wash-basin products has yet to be improved, and the product quality of each producing area may fluctuate, and it needs to be further consolidated and improved.It is necessary to further strengthen the publicity and implementation of standards, improve the quality awareness of production enterprises, consciously strengthen the internal quality management of enterprises, insist on not using the raw and auxiliary materials that do not meet the requirements of national standards, strengthen the incoming inspection of raw and auxiliary materials and the delivery inspection of products, and strengthen the management of all aspects of production. 


\section{Conclusion}

Spot check results basically reflect the actual situation of the face cleaner product industry, the quality of large and medium-sized enterprises is stable, the quality of small and micro enterprises is unstable, and the rate of unqualified discovery is higher.

Guangzhou, Henan two provinces as the output of face cleaner products, should play a role in the vanguard of the industry, to produce high quality, high performance, environmental protection and safety products for the purpose.In particular, local supervisory and administrative departments and trade associations should play a role in strengthening supervision, increasing the density of spot checks, and concentrating on the rectification of unqualified enterprises.It is of great significance for the overall development of the sanitary ware industry in China to effectively regulate the industry of Wash-basin in Guangdong Province and Henan Province as soon as possible.

\section{References:}

1. UNIDO. Quality Infrastructure[R], 2006.

2. GB/T 6952-2015 《Sanitary wares》.

3. Department of Science and Technology, AQSIQ. NQI: Consolidate the quality of the country strategy to lead the economic and social development [J]. Quality and Certification, 2016(4): 28-30.

4. Yanzhen, L. (2015) On the standardization of ceramic raw materials and the protection of resources and environment. Ceramics, No 11:9-13. 